\section{Parador y mirador} Pinohuacho, Chile
Esta obra de título, construida gracias a la participación de lugareños y el reciclaje de material abandonado propone un espacio de contemplación de un paisaje previamente explotado. Los volúmenes generados se disponen y entregan gratuitamente en el lugar, permitiendo reflexionar y volver a mirar su historia.

Rodrigo Sheward Arquitecto, Universidad de Talca
This thesis project, built thanks to the participation of locals and the recycling of abandoned material, proposes a contemplation space of a landscape previously exploited. The generated volumes are placed and give gratuity to the space, allowing one to reflect over history.

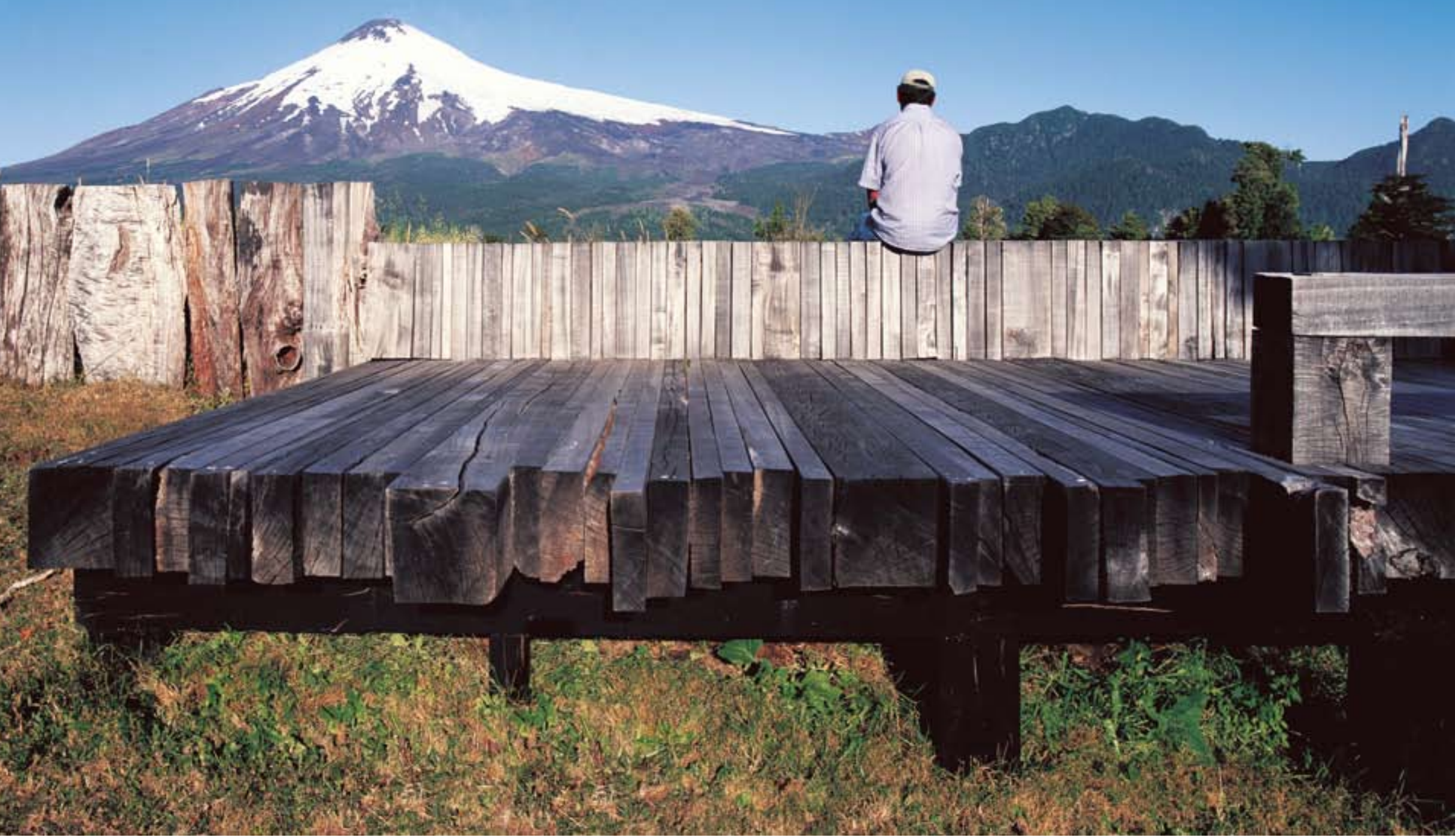




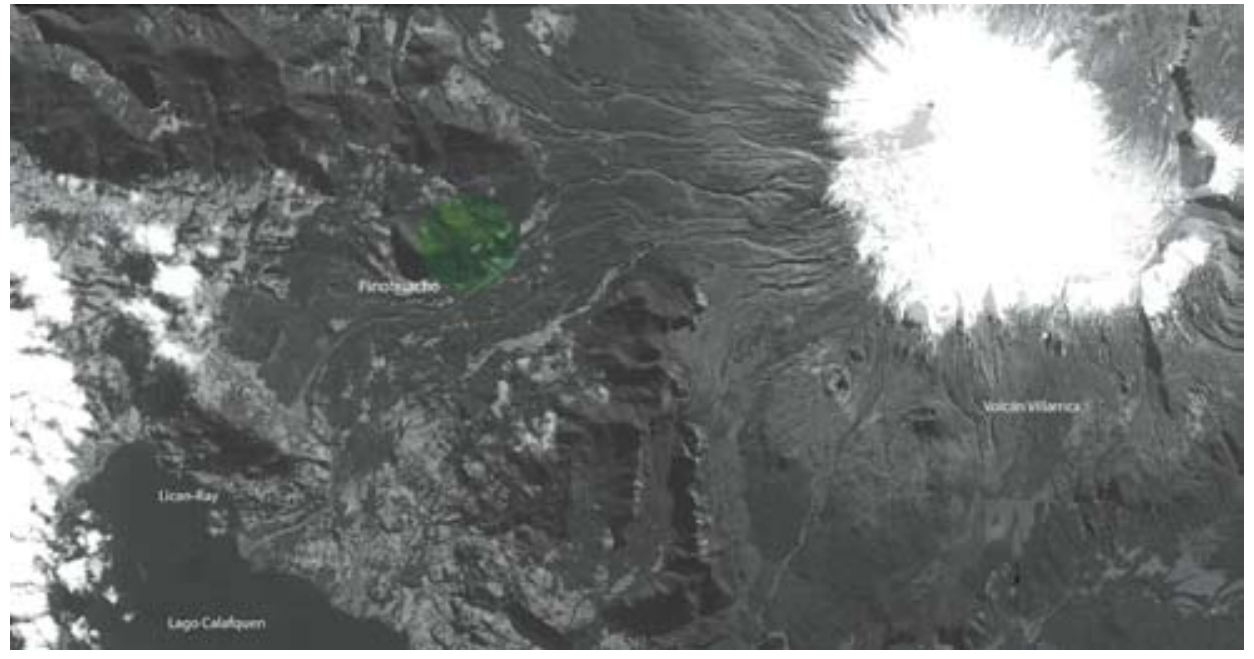

Emplazamiento parador y mirador, Pinohuacho, Chile. Fuente: Servicio de imágenes del planeta Google Earth ${ }^{T M}$

Una hora caminando por una sinuosa huella que se encumbra por las laderas de un cerro hasta llegar a su cima, entre bosques de renovales y vestigios de una antigua explotación maderera. La reconversión de este territorio significó el fin de la tala y la incursión en diversos rubros, todos ellos de subsistencia, como la plantación de papas y avena. Curioso encontrarse con flores violeta coronando las lomas despejadas que definen el límite del antiguo bosque y la superficie para el cultivo. ¿Qué hace esta arquitectura merodeando este lugar? Busca la conexión entre reflexión y obra, intentando definir un quehacer para el territorio.

El encargo primero ha sido de la Escuela de Arquitectura de la Universidad de Talca: llevar arquitectura donde no la hay, llegar donde el encargo no espera una respuesta. Darse un espacio que permita dialogar y para ello gestionar, diseñar y construir. Un camino sin pavimento para un arquitecto que proyecta su opera prima.

La obra está compuesta de dos volúmenes distantes $80 \mathrm{~m}$ uno de otro. El uno mira de perfil al volcán Villarrica, el otro de frente a los lagos Calafquén y Panguipulli. Una cerca construye el límite a los animales y la arista a los visitantes que acceden a caballo o a pie desde el bosque.

96 piezas de 10 x 120" conforman el cuerpo principal, que es bodega de acopio y permite a estas comunidades duplicar su producción.
En invierno será guarida de los cazadores de jabalí; en verano parador de excursionistas, curiosos y naturalistas.

Las 38 toneladas del casetón surgen como respuesta definitiva. Estos volúmenes están construidos con la historia material del lugar, no con la estrategia del andinista. Surgen de la voluntad del hacer.

Cada una de las piezas ocupadas fue recogida de cada uno de los árboles abandonados por la forestal. Cada pieza fue aserrada, modelada, espigada e inventada en el lugar.

La respuesta arquitectónica ha dado forma a una dilatada discusión académica, a una extensa conversación con los lugareños y a largas caminatas. Pero también al arduo trabajo del leñador que, probablemente, culmina sus días construyendo para el lugar con la misma voluntad con la que antaño lo devastó. ¿Por qué construir una obra de arquitectura en Pinohuacho? Esta respuesta viene dada por reconocer dos antecedentes a la obra. El primero es haber realizado los estudios de arquitectura en la Escuela de Arquitectura de la Universidad de Talca, lo cual trae consigo la preocupación de hacer arquitectura donde no la hay y con lo que hay. El segundo es haber establecido estrechas relaciones con una comunidad que se pregunta sobre qué hacer en el territorio que habitan y poner a disposición de éste su organización social y habilidades intrínsecas para construir su nuevo quehacer sobre aquel territorio devastado. ARQ
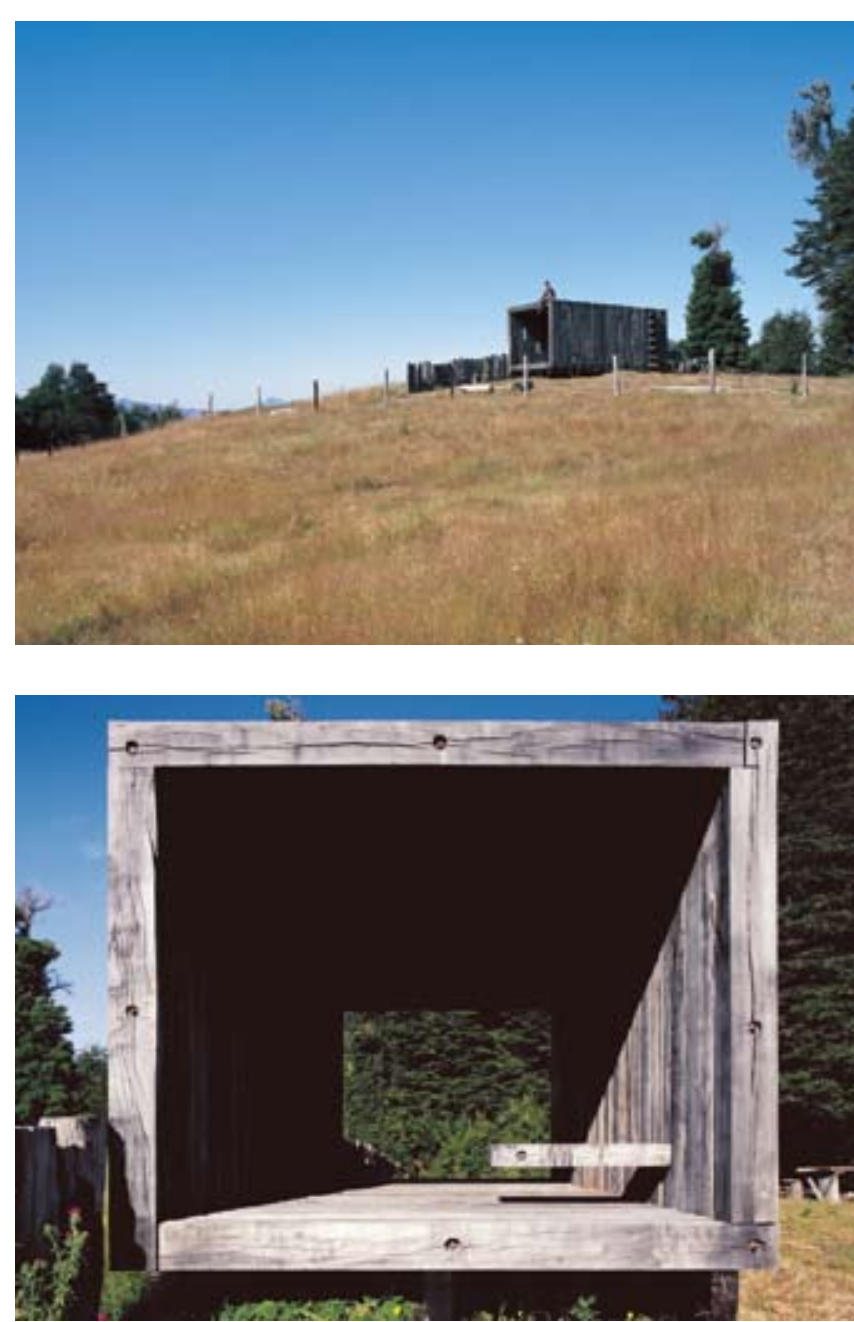

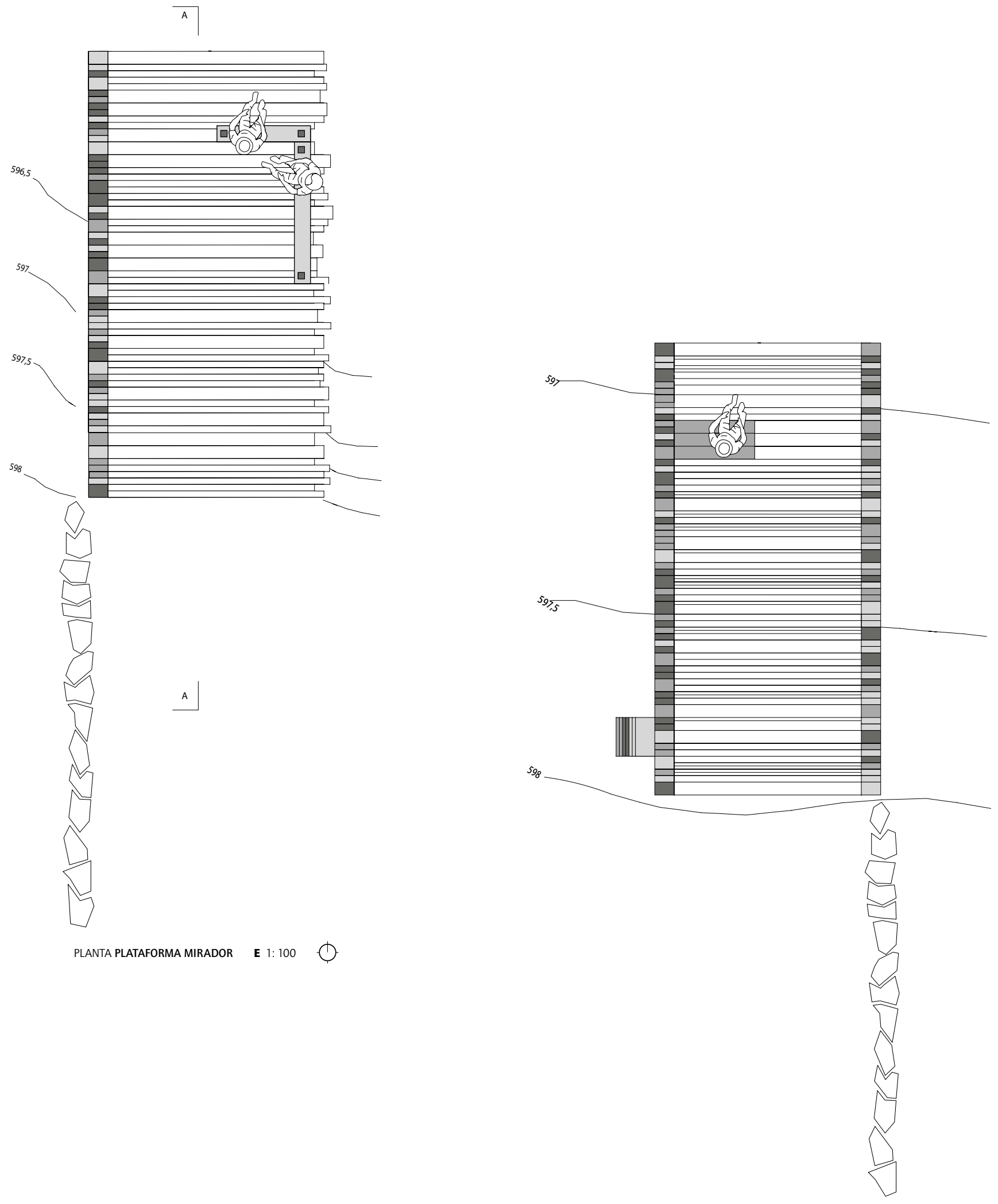


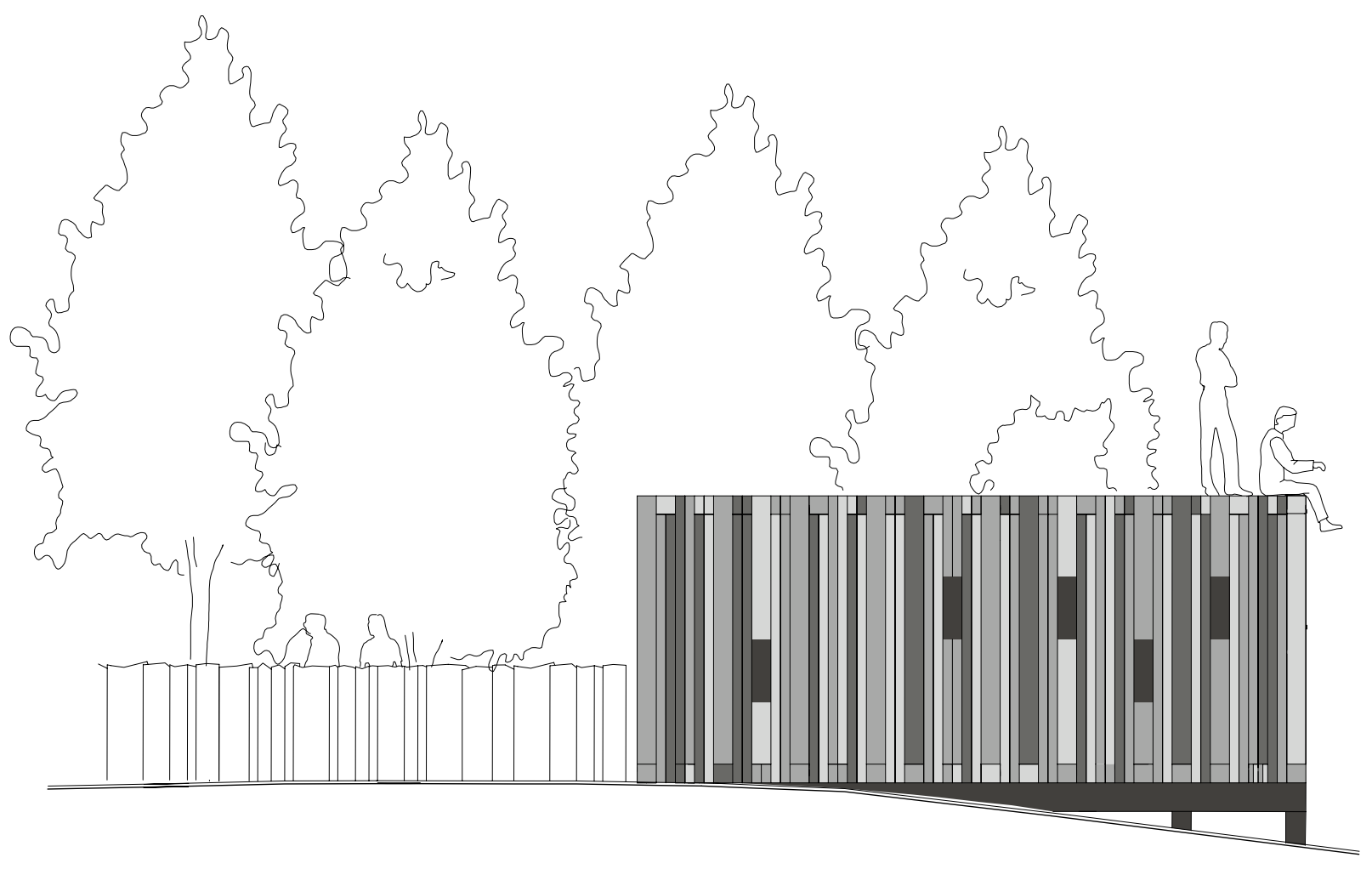

ELEVACIÓN ESTE CASETÓN DE ACOPIO E 1: 100

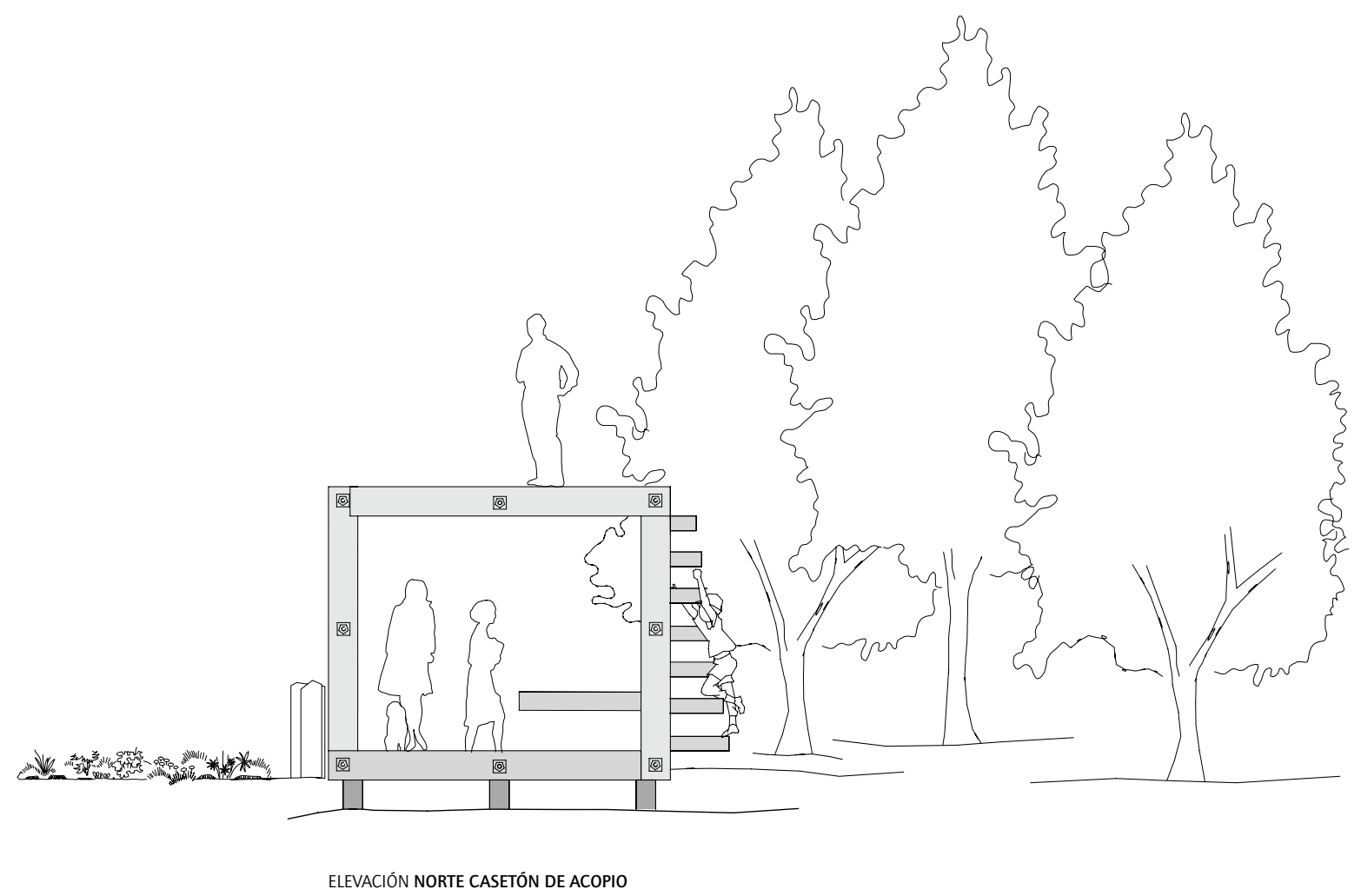



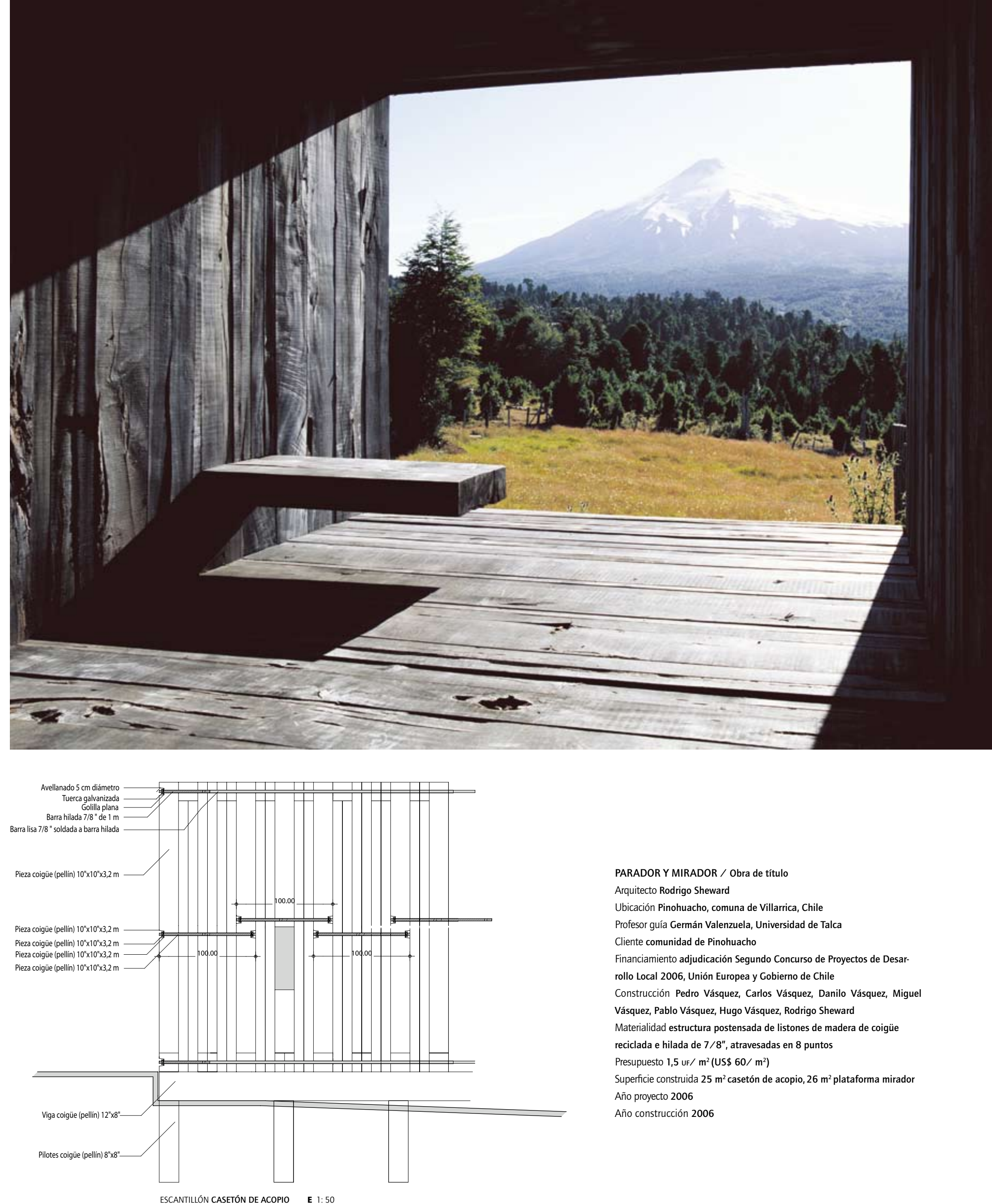

PARADOR Y MIRADOR / Obra de título

Arquitecto Rodrigo Sheward

Ubicación Pinohuacho, comuna de Villarrica, Chile

Profesor guía Germán Valenzuela, Universidad de Talca

Cliente comunidad de Pinohuacho

Financiamiento adjudicación Segundo Concurso de Proyectos de Desarrollo Local 2006, Unión Europea y Gobierno de Chile

Construcción Pedro Vásquez, Carlos Vásquez, Danilo Vásquez, Miguel Vásquez, Pablo Vásquez, Hugo Vásquez, Rodrigo Sheward

Materialidad estructura postensada de listones de madera de coigüe reciclada e hilada de $7 / 8^{\prime \prime}$, atravesadas en 8 puntos Presupuesto $1,5 \mathrm{uf} / \mathrm{m}^{2}$ (US $\$ 60 / \mathrm{m}^{2}$ )

Superficie construida $25 \mathrm{~m}^{2}$ casetón de acopio, $26 \mathrm{~m}^{2}$ plataforma mirador Año proyecto 2006

Año construcción 2006 